DOI: $10.17957 / \mathrm{IJAB} / 15.1768$

http://www.fspublishers.org

\title{
Fusarium incarnatum: A Novel Leaf Spot Pathogen Isolated from Rosa indica in Pakistan
}

\author{
Shazia Shafique ${ }^{1 *}$, Rubab Rafique ${ }^{2}$, Sobiya Shafique ${ }^{1}$, Abrar Hussain ${ }^{2}$, Alina Javed ${ }^{2}$ and Ayesha Mubarak $^{2}$ \\ ${ }^{1}$ Institute of Agricultural Sciences, University of the Punjab, Lahore, Pakistan \\ ${ }^{2}$ Department of Botany, University of Education, Township Campus, Lahore, Pakistan \\ *For correspondence: shazia.iags@pu.edu.pk; drshazi81@gamil.com \\ Received 15 October 2020; Accepted 06 February 2021; Published 16 April 2021
}

\begin{abstract}
Fungal leaf spots disease is a main reason of rose (Rosa indica L.) crop failure in Pakistan. Isolation and identification of pathogen from rose plant was done by observing phenotypic characters which were further executed on molecular bases using ITS, EF and $\mathrm{Bt}_{2} \mathrm{a} / \mathrm{Bt}_{2} \mathrm{~b}$ primers. On these bases, pathogen was identified as Fusarium incarnatum. Then, Koch's pathogenicity test was applied to confirm the virulence level of the isolated fungus by artificially inoculating it on $R$. indica seedlings in plate and pot trials. This study signifies the first report of $F$. incarnatum as a leaf spot pathogen of $R$. indica in Pakistan and highlights the need to explicate the management strategies of pathogen populations. (C) 2021 Friends Science Publishers
\end{abstract}

Keywords: Fusarium incarnatum; Leaf spots; Rosa indica; Morphology; ITS; Pathogenicity

\section{Introduction}

Rosa indica L. (Roseaceae family) is considered as an ancient crop cultivated about 5000 years ago. It is economically important in medicinal and health aspects. Some rose species are cultured on commercial scale for the production of aromatic rose oil, rose water, rose atar, gulkand, perfume industry etc. (Margina and Zheljazkov 1995; Wen and Deng 2005). Level of vitamin C is greater than oranges in roses which aid in comforting inflammation, sunburned and release indigestion. In Pakistan, 17000 acres area under flowering crops is projected more than because of its high demand (Taj et al. 2013). Rose is attacked by various pathogens like bacteria, viruses and fungi during their season of growth, preharvesting along with handling and transportation with post-harvest storage and marketing circumstances (Kakade et al. 2006). The common fungal infections of rose plants are dieback, stem blight, powdery mildew, many types of leaf spot and black spots that mainly destroy its beauty (Kakade et al. 2006). Leaf spot is largely caused by different pathogenic fungi viz., Alternaria and Fusarium etc. The disease has been spreading at an alarming rate and is responsible for significant losses to growers. Isolation and correct identification of pathogen is mandatory for the better management of disease. Thus, the aim of present study was to identify the cause of fungal leaf spots of rose plant as this phenomenon is requisite to stop or suppress fungal attack in roses.

\section{Materials and Methods}

During August-September 2018, leaf spot disease of rose plant was investigated in field survey of different areas of Punjab, Lahore. Infected plants showed symptoms of leaf necrosis, lesions and wilting. Data were recorded on the basis of size, colour and appearance of spots. For isolation of fungal pathogens, 3-4 spots at least were cut into $3 \mathrm{~mm}^{2}$ small pieces from infected leaf. About 4-5 of these leaf portions, were aseptically inoculated onto MEA plates and incubated at $25+3^{\circ} \mathrm{C}$ as suggested by Thom and Raper (1945). Disease causing fungal species was primarily recognised on morphological characteristics base (Colour of colony, conidiophore pattern of branching, number and size of conidia, etc). Then molecular identification of fungal isolates was further done by PCR primers viz., ITS1/ITS4, $\mathrm{EF} 1 / \mathrm{EF} 2$ and $\mathrm{Bt}_{2} \mathrm{a} / \mathrm{Bt}_{2} \mathrm{~b}$. Amplification was carried out using commercially available $2 \mathrm{X}$ Amp Master ${ }^{\mathrm{TM}}$ Taq polymerase (Gene all Biotechnology Co., Ltd.) in a total volume of 30 $\mu \mathrm{L}$ PCR reaction mixture. Nucleotide sequences of amplified PCR products were analysed by Nucleotide Basic Local Alignment Search Tool (BLAST) analysis. After BLAST analysis, resulting sequences homology were recorded using corresponding strains in GenBank database and further used for identification of fungal strains. MEGA 6 (Tamura et al. 2013) and Jukes-Cantor, model (Jukes and Cantor 1969) was used for evolutionary analysis with maximum likelihood method.

Subsequently, pathogenicity confirmation in in vitro conditions was conducted. Healthy leaves detached from

To cite this paper: Shafique S, R Rafique, S Shafique, A Hussain, A Javed, A Mubarak (2021). Fusarium incarnatum: A novel leaf spot pathogen isolated from Rosa indica in Pakistan. Intl J Agric Biol 25:1096-1100 
rose plants were placed in petri plates on moistened filter papers. Leaves were surface disinfested with hypochlorite solution $(0.5 \%)$ before placing in Petri-plates. Under aseptic conditions $100 \mathrm{~mL}$ of sterilized $\mathrm{NaCl}$ solution was prepared. Spores from 7 days old pure fungal culture were scratched and suspended in saline solution. Then serially diluted to prepare a suspension containing $4 \times 10^{4}$ spores $\mathrm{mL}^{-1}$ using haemocytometer and further used as inoculum (French and Hebert (1982). In aseptic conditions, $2 \mathrm{~mL}$ spore suspension $\left(4 \times 10^{4}\right.$ spores $\left./ \mathrm{mL}\right)$ was sprayed on the surface area of the leaf (Farrag and Abo-Elyousr 2011; Akhter et al. 2015). Appearance of disease symptoms was observed regularly during incubation at $25+3^{\circ} \mathrm{C}$. To confirm postulate, the pathogen was re-isolated from these infected necrotic lesions of leaves. The pathogenicity was further confirmed by in vivo pot trial. The soil was sterilized in hot air oven at $45^{\circ} \mathrm{C}$ for $24 \mathrm{~h}$ to preserve natural organic matter. Then pots were levelled with soil $\left(1 \mathrm{~kg} \mathrm{pot}^{-1}\right)$. The grafted rose stems were sown and watered properly in growth room at $30+$ $2^{\circ} \mathrm{C}$. Spore suspension $(15 \mathrm{~mL})$ in sterilized syringe was injected on rose stem nodes and in soil to confirm the pathogenicity. Distilled water was used as control. Polythene bags were used to cover the plants for $48 \mathrm{~h}$ to maintain the moisture for spore germination and disease development. The symptoms started to appear within 2-3 days. Disease severity was measured after visual estimation using Horsfall-Barratt scale (Horsfall and Barratt 1945).

\section{Results}

During survey, disease symptoms were noticed as a number of dark browns to black necrotic spots and lesions on the leaves. The size of the spots was $2-3 \mathrm{~mm}$ and about 50 $60 \%$ area of leaves was found to be infected with disease.

Diseased leaves of rose plant were subjected to trials for isolation of fungal pathogen. The isolated fungus was purified by the hyphal tip method and then identified by its morphological features and microscopic characters (Barnett and Hunter 1972). The culture color of isolated fungus was light peach in its center with white color from edges. Colony size was measured about $3.3 \mathrm{~cm}$ in incubated time period of seven days. Mycelium was densely packed with long tufts or hairy structure, became darker peach in shade with the maturity. Microscopic analysis revealed single celled micro conidia which were without any septation, hyaline and ovoid, $10-12 \times 3-4 \mu \mathrm{m}$ in size. Macro-conidia were 4-5 septate, basal cells were attached with long stalk, pointed apical end, moderately curved (Fig. 1). The isolated fungus was identified as Fusarium incarnatum.

Following the morphological identification, the isolated DNA of the fungal culture was used in PCR amplifications by internal transcribe sequence spacer (ITS), elongation factor $(\mathrm{EF})$ and $\beta$-tubulin primers for molecular confirmation of fungal pathogen. Amplification impressions revealed that all the PCR products of ITS region of pathogenic fungus expressed the nucleotide sequences of

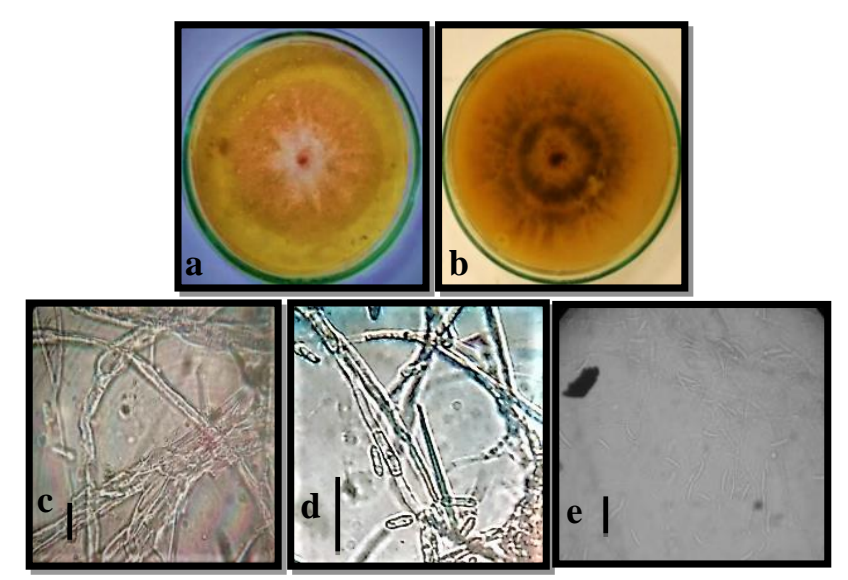

Fig. 1: F. incarnatum (a) Front side (b) reverse side of colony (cd) microphotographs of mycelia and microconidia at $40 \mathrm{X}$ and $100 \mathrm{X}$ magnification of microscope, respectively, (e) macroconidia at $40 \mathrm{X}$. Scale bar: $\mathrm{c}$ and $\mathrm{e}=10 \mu \mathrm{m}, \mathrm{d}=20 \mu \mathrm{m}$

$540 \mathrm{bp}$ on agarose gel. $\beta$-tubulin sequences of $300-400 \mathrm{bp}$ in length and $\mathrm{EF}$ sequences were $250 \mathrm{bp}$ in length were amplified.

Nucleotide sequences were evaluated by "BLAST" NCBI website. The fungal species identification was confirmed on the similarity basis of Blast sequences (90$100 \%$ ). The most precise method of Phylogenetic tress was used for F. incarnatum taxonomy.

Based on ITS sequence, the phylogenetic tree cladogram represented that the clades largely comprise of $F$. incarnatum and sub-clades of $F$. chlamydospore, $F$. moniliforme and $F$. incarnatum. The Blast analysis of sequence of ITS region revealed that it had $99.60 \%$ similarity with strain KP641161.1, strain MT565585.1 and strain MN871564.1. The homology of $99.40 \%$ was depicted with $F$. incarnatum MT560229.1 in GenBank database (Fig. 2A). This nucleotide sequence was deposited to Genbank under accession number MN544938.

The phylogenetic cladogram of $F$. incarnatum based on $\beta$-tubulin primer revealed that clades comprise of Fusarium equisetti as well but more similarity with $F$. incarnatum was detected. Blast analysis of $F$. incarnatum with partial Beta tubulin primer gave $98.35 \%$ similarity with the MN233576.1 strain; MK347263.1 strain and MK3472662.1 while $98.96 \%$ of similarity with $F$. incarnatum MK439850.1 (Fig. 2B). When the homologies searches were carried out for translation elongation factor (EF) sequence of $F$. incarnatum exhibited $99.59 \%$ similarity with $F$. incarnatum strains (KF962948.1), (JX971222.1), (MW059021.1) and (HE647907.1) and (GQ339798) in GenBank database (Fig. 2C).

In pathogenicity analysis by detached leaf method, appearance of symptoms was visible on the leaves in petriplates within 2 days of inoculum application. Initially, yellowing appeared on the leaves after $48 \mathrm{~h}$, followed by complete death of plant within 15 days. 


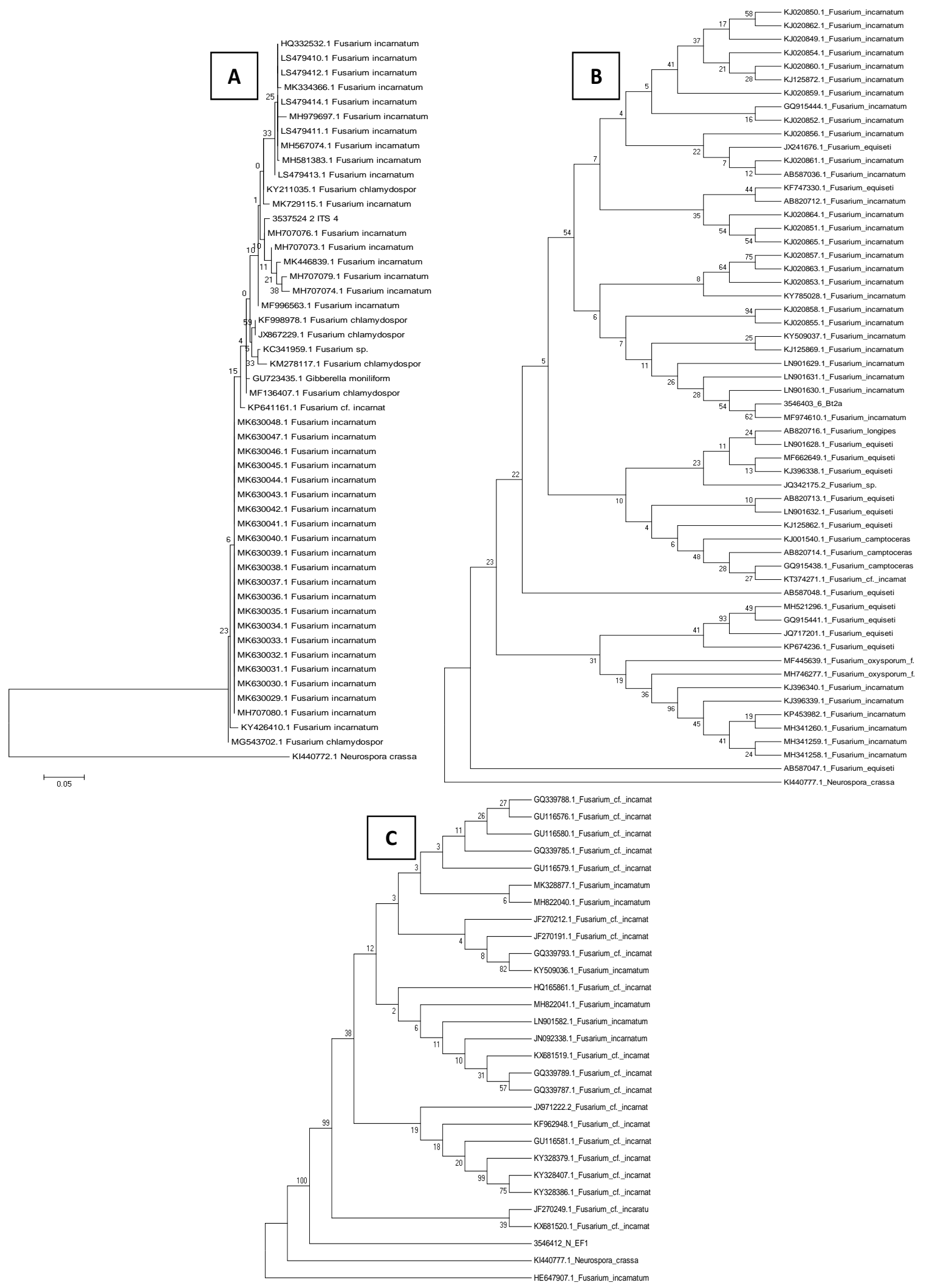

Fig. 2: Phylogenetic tree of $F$. incarnatum. MEGA 6 and Jukes- Cantor model was used for evolutionary analysis with maximum likelihood method. (A): Internal Transcribe Spacer (ITS) region of rDNA (B): $\beta$-tubulin region of rDNA (C): translation Elongation Factor $(\mathrm{EF})$ region of rDNA 


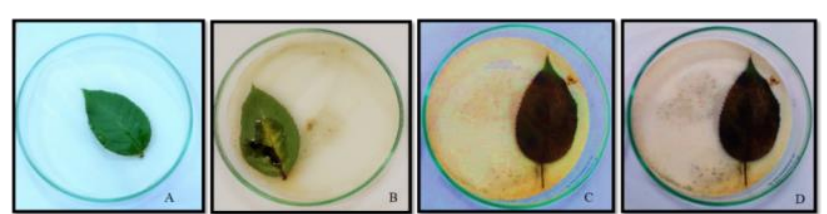

Fig. 3: Disease symptoms caused on $R$. indica by $F$. incarnatum (A) Control, Appearance of symptoms (B) after 3 days, (C) after 9 days, (D) after 15 days

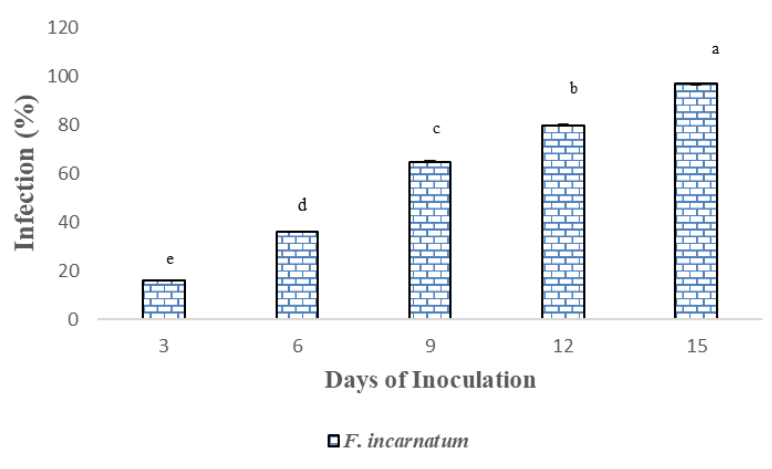

Fig. 4: Analysis of disease severity by $F$. incarnatum on $R$. indica Values with different letters show significant difference by ANOVA as determined by statistix 8.1 software, LSD test at $P \leq 0.05$

$F$. incarnatum attacked on midrib vein and tip of the leaf laminae at the very beginning but showed wilting symptoms at the end. With the passage of time, after 15 days disease progress was observed very sharp on the leaves in petri plates and $99 \%$ of the leaf area was observed to be infected (Fig. 3).

Further confirmation of pathogenic potential of $F$. incarnatum in field was done by spraying fungal pathogen on leaves of $R$. indica plants (1 month age) in pots. Appearance of infection was very slow at the primary stages. Initially foliar tips started to turn black in color. Consequently, symptoms were perceived to spread on the middle and lower sides of leaves. There were small circles of brown to black in color possibly necrosis spots along with drooping of aerial parts of the foliage. Fusarium incarnatum proved very virulent pathogen as it indicated $97 \%$ disease severity (Fig. 4). In response to severe pathogenic attack almost complete falling of rose leaves was observed.

\section{Discussion}

$R$. indica has notable place in every garden and also known to have nutritional as well as medicinal importance. But for most of instance, rose gardens have to face many types of foliar diseases mainly leaf spots that destroy its beauty. Leaf spot is largely caused by different pathogenic fungi. The disease has been spreading at an alarming rate and is responsible for significant loss to growers. To control this disease, it's necessary to isolate and identify the pathogen. For identification of fungal pathogens, initially conventional and reliable morphology method was in practice.
Subsequently, molecular techniques are also used to identify the fungi i.e., phylogenetic relationship between fungal groups (Mirhendi et al. 2007) and the use of mitochondrial small subunit (SSU) rDNA sequence (Kretzer et al. 1996) etc. In present study, $F$. incarnatum was isolated and identified as $R$. indica leaf spot causal agent by morphology and molecular techniques of nucleotide sequencing of rDNA using ITS, $\beta$-tubulin and EF primers. Previously, same method of morphological characterization followed by identification using rDNA nucleotide sequencing was used by Akhtar et al. (2016) for the isolation of pathogen Phyllosticta aristolochiicola from the Sonchus oleracus leaf spots. In the contemporary lines, Alternaria ochroleuca was recognized as a leaf spot causing pathogen of money plant on the basis of morphological characterization followed by identification using rDNA (Shafique et al. 2017). Fusarium incarnatum-equiseti species complex were isolated from Cucurbita pepo by Thomas (1998).

Furthermore, Koch's postulates were applied to evaluate the pathogenicity of $F$. incarnatum on $R$. indica seedlings by detached leaf and pot trial technique. Fusarium showed maximum brown to reddish spot with sharp disease curve by displaying maximum infected leaf area of $99 \%$. Working on parallel lines, Conner (2002) used detached leaf method to confirm the pathogenicity of Cladosporium carygenum on Pecans. Similarly, pathogenicity of different strains of $F$. oxysporum was confirmed by Koch's postulate on ten different varieties of Chili plant using pot trials. The particular symptoms were apparent after 10 days of inoculation by all the strains. However, strain B of $F$. oxysporum induced the distinctive symptoms within 7 days thus declared as the most pathogenic (Shafique et al. 2015).

\section{Conclusion}

This study emphasizes the need for management of $F$. incarnatum as an important strategy for the survival of ornamental plant $R$. indica.

\section{Author Contributions}

Shazia Shafique and Sobiya Shafique: Conceptualization, Methodology, Data curation, Writing, Reviewing and Editing Resources. Rubab Rafique: Investigation, Validation, Software, Data curation, Writing original draft. Abrar Hussain: Supervision. Alina Javed: Software, Investigation. Ayesha Mubarak: Software, Investigation.

\section{Conflict of Interest}

The authors have no conflict of interests to declare.

\section{Data Availability}

The original data will be made availabel upon convincing requests to the corresponding author. 


\section{Ethics Approval}

Not applicable.

\section{References}

Akhtar N, A Naseer, S Shafique, S Shafique, K Hanif, R Hafeez (2016). First Report of Phyllosticta aristolochiicola Causing Leaf Spot of Sonchus oleraceus in Pakistan. Plant Dis 100:1503-1503

Akhter N, A Naseer, S Shafique, S Shafique, R Hafeez (2015). First report of Alternaria arborescens causing leaf spot of Dracaena mariginata in Pakistan. J Plant Pathol 97:S-67-S77

Barnett HL, BB Hunter (1972). Illustrated Genera of Imperfect Fungi, $3^{\text {rd }}$ Edition, p:241. Burgess Publishing Co., Minneapolis

Conner J (2002). A detached leaf technique for studying race-specific resistance to Cladosporium caryigenum in Pecans. Amer Soc Hortic Sci 127:781-785

Farrag ESH, KA Abo-Elyousr (2011). Occurrence of some fungal diseases on datepalm trees in UpperEgypt and its control. Plant PatholJ 10:154-160

French ER, TT Hebert (1982). Phytopathological Research Methods, p:275. IICA San Jose Costa Rica

Horsfall JG, RW Barratt (1945). An Improved Grading System for Measuring Plant Disease. Phytopathology 35:655

Jukes TH, CR Cantor (1969). Evolution of protein molecules. In: Mammalian Protein metabolism, Vol. 4, pp:21-132. Munro HN (Ed.). Academic Press, New York, USA

Kakade DS, SB Gurav, BR Singh, CA Nimbalker (2006). Management of Powdery Mildew in Rose Under polyhouse Condition. J Ornament Hortic I 9:293-294
Kretzer A, Y Li, T Szaro, TD Bruns (1996). Internal transcribed spacer sequences from 38 recognized species of Suillus sensu lato: Phylogenetic and taxonomic implications. Mycologia 88:776-785

Margina A, V Zheljazkov (1995). Fungal pathogens from Uredinales on some medicinal and aromatic plants in Bulgaria and their control. In: International symposium on medicinal and aromatic plants, Vol. 426, pp:333-344. Amherst, Massachusetts

Mirhendi H, K Diba, A Rezaei, N Jalalizand, L Hosseinpur, H Khodadadi (2007). Colony PCR is a rapid and sensitive method for DNA amplification in yeasts. Iran J Publ Health 36:40-44

Shafique S, M Rafique, N Akhtar, S Shafique (2017). Identification and management of Alternaria ochroleuca - a cause of leaf necrosis in money plant. J Anim Plant Sci 27:1276-1286

Shafique S, M Asif, S Shafique (2015). Management of Fusarium oxysporum f. spp. capsici by leaf extract of Eucalyptus citriodora. Pak J Bot 47:1177-1182

Taj S, MTI Khan, M Abbas, A Bashir (2013). Price spread and marketing margins of cut rose in Punjab, Pakistan. Pak J Agric Res 26:16-23

Tamura K, G Stecher, D Peterson, A Filipski, S Kumar (2013). MEGA6: Molecular evolutionary genetics analysis version 6.0. Mol Biol Evol 30:2725-2729

Thom C, KB Raper (1945). A manual of the Aspergilli, Vol. 60, p:333. LWW

Thomas AZ (1998). Fusarium Diseases of Cucurbits Department of Plant Pathology, p:733. Cornell University, New York, USA

Wen XP, XX Deng (2005). Micropropagation of chestnut rose (Rosa roxburghii Tratt) and assessment of genetic stability in in vitro plants using RAPD and AFLP markers. J Hortic Sci Biotechnol 80:54-60 